\title{
Management of inflammatory bowel disease in the COVID-19 era
}

\author{
Kyeong Ok Kim, Byung Ik Jang \\ Division of Gastroenterology and Hepatology, Department of Internal Medicine, Yeungnam University College of Medicine, Daegu, Korea
}

During the coronavirus disease 2019 (COVID-19) pandemic, many unpredictable changes have occurred in the medical field. Risk of COVID-19 does not seem to increase in patients with inflammatory bowel disease (IBD) considering based on current reports. Current medications for IBD do not increase this risk; on the contrary, some of these might be used as therapeutics against COVID-19 and are under clinical trial. Unless the patients have confirmed COVID-19 and severe pneumonia or a high oxygen demand, medical treatment should be continued during the pandemic, except for the use of high-dose corticosteroids. Adherence to general recommendations such as social distancing, wearing facial masks, and vaccination, especially for pneumococcal infections and influenza, is also required. Patients with COVID-19 need to be withhold immunomodulators or biologics for at least 2 weeks and treated based on both IBD and COVID-19 severity. Prevention of IBD relapse caused by sudden medication interruption is important because negative outcomes associated with disease flare up, such as corticosteroid use or hospitalization, are much riskier than medications. The outpatient clinic and infusion center for biologics need to be reserved safe spaces, and endoscopy or surgery should be considered in urgent cases only. (Intest Res 2022;20:3-10)

Key Words: Inflammatory bowel disease; Coronavirus; COVID-19; SARS-CoV-2

\section{INTRODUCTION}

Since the first report in December 2019 from Wuhan, China, coronavirus disease 2019 (COVID-19) has rapidly spread and affected lives globally. ${ }^{1,2}$ It is caused by severe acute respiratory syndrome coronavirus 2 (SARS-CoV-2), which is highly infectious, with a fatality rate of $2 \%$ to $3 \%{ }^{3}$ The risk of mortality or severe infection requiring intensive care unit (ICU) hospitalization increases with age and underlying comorbidities. ${ }^{4,5}$

Inflammatory bowel disease (IBD) is a chronic immunemediated disease, requiring the use of immunomodulatory and immunosuppressive drugs. This could make IBD patients susceptible to COVID-19. However, early reports from China

Received December 7, 2020. Revised December 31, 2020.

Accepted January 4, 2021.

Correspondence to Byung Ik Jang, Division of Gastroenterology and

Hepatology, Department of Internal Medicine, Yeungnam University College of Medicine, 170 Hyeonchung-ro, Nam-gu, Daegu 42415, Korea. Tel: +82-

53-650-4092, Fax: +82-53-621-4487, E-mail: jbi@med.yu.ac.kr and Italy showed that no IBD patient developed COVID-19., To date, there are limited data regarding IBD and COVID-19, but evidence with a higher quality has been gradually accumulated recently. We aimed to review the management of IBD in the COVID-19 era.

\section{RISK OF COVID-19 IN IBD PATIENTS}

In addition to fever and respiratory symptoms, ${ }^{8}$ about $15 \%$ of COVID-19 patients complain of gastrointestinal symptoms such as diarrhea, nausea, vomiting, and anorexia, with variable frequencies. ${ }^{9}$ These symptoms are more likely to be noted in patients with severe COVID-19. ${ }^{10}$ This could be associated with the expression of angiotensin conversion enzyme 2 (ACE2) and transmembrane protease serine protease 2 (TMPRSS2) in the enterocytes, which play an important role in the entrance of viruses into human cells and the regulation of the binding to the receptors. ${ }^{11,12}$ Interestingly, ACE2 and TMPRSS2 were 
upregulated in the inflamed bowel of patients with $\mathrm{IBD},{ }^{13}$ thereby increasing the susceptibility of IBD patients to SARS-CoV-2. In addition, IBD patients could be at increased risk of SARSCoV-2 infection due to the medications they use, i.e., immunosuppressants or immune-modifying drugs. However, based on the pooled analysis data, the prevalence of COVID-19 is not higher in IBD patients than in the general population. ${ }^{14-16}$ This could be partly explained by the elevated soluble form of ACE2, a competitive receptor for the virus, in the serum of IBD patients that protects the host from viral infection. ${ }^{17}$ Another study also reported that ACE2 expression has dual action: mediating the susceptibility and immunity to SARS-CoV-2 infection. ${ }^{18}$ In addition, a recent animal study reported that drugs for IBD, such as steroids or biologics, could decrease the ACE2 expression in inflammatory cells. ${ }^{19}$

The risk factors of SARS-CoV-2 infection specific for IBD patients are not fully understood, and immunosuppressive medication, malnutrition, comorbidities, advanced age, active IBD symptoms, and frequent visits to clinics or hospitals have been reported. ${ }^{6,20-24}$ Although we are not sure whether bowel inflammation is a risk factor for COVID-19, maintaining remission is important in IBD patients. ${ }^{25}$

\section{MEDICATIONS USED FOR IBD, AND RISK OF COVID-19}

There are limited data on the safety of drugs used for IBD during the COVID-19 pandemic, and the evidence level is also low. Experts or several societies proposed recommendations based on SARS, Middle East respiratory syndrome (MERS), or few reported case series. Generally, continuation of immunosuppressive drugs with close monitoring is recommended for patients who are already on stable maintenance. ${ }^{26,27}$ In contrast, it is recommended to delay the initiation or escalation of new immunosuppressive drugs, if possible. ${ }^{23}$ Prevention of IBD relapse due to sudden interruption of medication is important because negative outcomes associated with disease relapse, such as new prescription of corticosteroids or hospitalization, are much riskier than medications. ${ }^{28}$

\section{5-Aminosalicylates}

The oral or suppository and enema formulations have little effect on the clinical course of COVID-19 because they act locally. Therefore, these should be continued. ${ }^{6,29}$ However, data from the Surveillance Epidemiology of Coronavirus Under Research Exclusion-IBD (SECURE-IBD) registry reported that patients treated with 5-aminosalicylates (5-ASA)/sulfasalazine showed a higher risk of severe COVID-19 defined as ICU admission, ventilator use and/or death than those treated with anti-tumor necrosis factor (TNF) agents. ${ }^{30}$ Further studies on the clinical outcomes associated with 5-ASA are required.

\section{Corticosteroids}

Corticosteroids are commonly used for the management of IBD because of their potent anti-inflammatory activity. They could also be useful to control excessive inflammatory conditions, including acute lung injury, acute respiratory distress syndrome, and septic shock. ${ }^{31}$ However, previous studies on their effect in MERS, SARS, and influenza showed a delayed clearance of the virus and poor clinical outcomes in patients continuing corticosteroids. ${ }^{32,33}$ Based on these findings, routine corticosteroid use is not recommended in patients with COVID-19 unless in the presence of complications. ${ }^{34}$

Likewise, corticosteroid use should be minimized and quickly tapered for doses over $20 \mathrm{mg}$ /day of prednisolone or equivalent considering the disease activity. In addition, prescription of new corticosteroids should be avoided. For safety reasons, the use of topical steroids or oral budesonide could be good. ${ }^{29}$

When we consider the use of high-dose systemic corticosteroids in such cases with acute severe ulcerative colitis (UC), it is recommended to manage based on the urgent COVID-19 swab results or clinical symptoms. Intravenous steroids might be introduced in patients negative for COVID-19 symptoms irrespective of the swab results. However, due to the uncertain risk of benefits in patients with COVID-19 pneumonia, experts have given high score to corticosteroids as first-line treatment, even in positive cases with respiratory symptoms or imaging studies. $^{35}$

\section{Immunomodulators}

Azathioprine and mercaptopurine play an important role in maintenance of IBD remission, and they exhibit direct or indirect antiviral activity by inhibiting viral proteases and proteins related to the viral replication process. ${ }^{36,37}$ However, there is a report on serious viral infection in IBD patients on thiopurine. ${ }^{38}$ Although there is no current evidence on the increased risk of COVID-19 infection, the initiation and dose escalation of immunomodulatory drugs is considered inappropriate during the pandemic. Patients already taking these drugs and controlled well, should continue these, and methotrexate can also be continued, as usual, unless the patients are infected or exposed to the virus. ${ }^{29}$ 


\section{Biologics}

Patients taking biologics should continue these if they are already in remission. Although in the COVID-19 pandemic period stopping biologics could be considered only when the same criteria in the pre-pandemic period are satisfied unless they are infected. ${ }^{29}$ To date, routine screening for COVID-19 before the initiation of biologics remains controversial. ${ }^{39,40}$

\section{1) Anti-TNF}

Although there are limited available data, evidence shows that anti-TNF agents, including infliximab, adalimumab, and golimumab, have little effects on the clinical course of COVID-19. ${ }^{6-8,15}$ Control of active inflammation induced by TNF inhibition can attenuate the cytokine storm due to COVID-19 infection.

Intravenous injections are not encouraged due to the concern associated with visiting hospital during the pandemic. Although subcutaneous biologics (adalimumab or golimumab) are safe and convenient during the pandemic, there is a risk of loss of response due to routinely switching drugs. ${ }^{41}$ In this pandemic period, the initiation of combination with immunomodulators and anti-TNF agents is recommended to be delayed. In patients who are already on combination therapy, discontinuation of immunomodulators is also recommended if they are in deep remission. ${ }^{42}$

\section{2) Vedolizumab and Ustekinumab}

Vedolizumab, gut-selective anti-integrin has a little impact on systemic or pulmonary response and Ustekinumab, antiinterleukin (IL)-12/23 monoclinal antibody is also less systemic; therefore, both drugs might be safer than anti-TNF in COVID-19 patients. ${ }^{29,43}$ Vedolizumab and ustekinumab did not increase the risk of severe respiratory tract or opportunistic infections in long-term follow-up studies. ${ }^{44-47}$ Considering safety, the use of vedolizumab or ustekinumab could be better options in the COVID-19 pandemic when initiating biologic therapy. ${ }^{42}$

\section{Small Molecule Drug}

There are no data on the risk of using Janus kinase (JAK) inhibitors, including tofacitinib, in COVID-19. A study on rheumatoid arthritis reported that $18.8 \%$ of patients had upper respiratory tract infection and $16.6 \%$ of patients had nasopharyngitis, and the result was similar to that reported by a study on anti-TNF. ${ }^{48}$ Another study also reported no increased hospitalization rate in patients with COVID-19 treated with JAK inhibitors. ${ }^{49}$
However, research has shown that JAK inhibitors reduce the levels of interferon- $\alpha$, which is an important cytokine conveying immunity against viruses, and tofacitinib use has shown an increased risk of herpes zoster in $5.6 \%$ of UC patients. ${ }^{50} \mathrm{We}$ also need to be careful about the risk of thromboembolism associated with tofacitinib because COVID-19 infection has a strong association with hypercoagulability. ${ }^{51}$ Considering these safety concerns, initiation of tofacitinib is not recommended during this pandemic. If the patients are in remission, we can maintain a daily dose of $10 \mathrm{mg}$ ( $5 \mathrm{mg}$ twice) of tofacitinib. Based on clinical trials on tofacitinib, factors associated with serious infection include a higher dose ( $10 \mathrm{mg}$ twice per day), age $>65$ years, use of corticosteroids higher than $7.5 \mathrm{mg} /$ day, and presence of diabetes. ${ }^{52,53}$

\section{Drugs in Clinical Trials}

In the early phase of the pandemic, many clinical trials had stopped most of their process. In Korea, recruitment and screening re-started after a review of the suitability of each center. There is a need for a balance between the benefit and unpredictable risk of trial medication during COVID-19. The Asia Pacific guidelines suggest that patients participating in clinical trials should continue taking the medication unless they develop COVID-19. ${ }^{29}$ To minimize the risk, direct hospital visits of study subjects have to be considered only in clinically important condition, otherwise, changed into virtually if possible. $^{54}$

\section{GENERAL MANAGEMENT FOR IBD IN COVID-19 PANDEMIC}

The strategy to manage IBD patients should be individualized based on the risk associated with infection and IBD activities. The IBD COVID-19 working group of British Society of Gastroenterology (BSG) classified IBD patients into 3 categories based on the degree of risk for poor outcomes of COVID-19. Patients with the highest risk were defined as IBD patients with comorbidities and/or $\geq 70$ years on moderate risk therapy such as biologics, small molecular drugs immunomodulators, or prednisolone $<20 \mathrm{mg} /$ day. Regardless of comorbidities or age, IBD patients taking $>20 \mathrm{mg}$ of prednisolone, biologics combined with immunomodulators or steroids, uncontrolled moderate-severe disease activity, and requiring parenteral nutrition are also considered as high risk. Patients at high risk are recommended "shielding" and to stay at home, except for specific purposes. They are advised to avoid gatherings, ex- 
cept families living with them and those working at home. Patients younger than 70 years taking moderate risk medications and do not have comorbidities are classified as moderate risk and they are recommended "stringent social distancing." The lowest risk group included patients on conventional medications such as mesalamine (both oral or topical agents), topically acting steroids (budesonide or beclomethasone), antidiarrheals or antibiotics. They were recommended "social distancing." ${ }^{54}$

Meticulous adherence to general recommendations during COVID-19 is needed in patients with IBD, including frequent hand washing, maintaining social distancing, no touching, and constant use of mask. ${ }^{26}$ Besides, the European Crohn's and Colitis Organisation-COVID (ECCO-COVID) taskforce suggested avoiding contact with infected people, crowded places, and traveling. They also emphasized that vaccination, including against influenza and pneumococcal infections, is needed for IBD patients treated with immunomodulators or biologics. ${ }^{55}$ Because nutrition is also an emerging prognostic factor, early intervention and support are warranted. ${ }^{56}$

\section{PRACTICE IN IBD CLINICS}

During the world wide spread of infection, most experts suggested telemedicine instead of face-to-face medical consultations if the disease is stable. ${ }^{29,57,58}$ Telemedicine was also temporarily accepted during the pandemic in Korea. Routine laboratory tests are deferred until the situation improved. Safe space in hospitals for patients who need close follow-up is required ${ }^{29}$ For patients on biologics, the infusion room secure a 1-2 m distance between infusion chairs. ${ }^{26}$ Routine screening for suspected symptoms of COVID-19, such as fever or cough, is required at each visit. Precautions including wearing masks and personal hygiene during visiting and infusions are also warranted. ${ }^{29}$ A single occupancy room is used for patients requiring hospitalization. ${ }^{23}$

\section{ENDOSCOPY}

With the presence of SARS-CoV-2 RNA in the stool of COVID-19 patients, there are concerns about fecal-oral transmission. Colonoscopy could also be a potential infection route, similar to esophagogastroduodenoscopy. ${ }^{11,57,58}$ Based on these, elective endoscopies are to be delayed unless they were critical for the management decision; instead, noninvasive markers such as C-reactive protein and fecal calprotectin could be used for disease monitoring. ${ }^{29}$ However, patients with severe symptoms or suspected emergencies such as acute severe flare-up, obstruction, or cholangitis require urgent endoscopy for diagnosis and proper management. ${ }^{59}$

Endoscopic practice during COVID-19 could be performed based on the guidelines of each society. Because we are not sure how long the pandemic will continue, surveillance colonoscopy for longstanding IBD in patients with risk factors such as a history of dysplasia, stricture, or histological inflammation might be recommended based on the guidelines. ${ }^{60,61}$ The order of endoscopy re-start after the pandemic or infection is based on clinical symptoms, blood or stool test results, use of biologics, or a history of dysplasia or cancer. ${ }^{59,62}$

\section{CLINICAL OUTCOMES AND MANAGEMENT OF IBD PATIENTS WITH CONFIRMED SARS-COV-2 INFECTION}

SECURE-IBD, the ongoing global registry data, has reported 3,195 cases until November 2020: $21 \%$ of patients were hospitalized and $6 \%$ patients required a ventilator or ICU care or who died. ${ }^{63}$

Data on the prognostic factors of COVID-19 in IBD are limited. The first COVID-19 data with 79 IBD patients from Italy showed that age $>65$ years (odds ratio [OR], 5.87; 95\% confidence interval [CI], 1.15-29.66), Charlson comorbidity index $>1$ (OR, 2.91; 95\% CI, 1.06-9.21), and UC diagnosis (OR, 2.72; 95\% CI, 1.06-6.99) were significant risk factors for poor outcomes of COVID-19. ${ }^{24}$

American Gastroenterological Association suggested a treatment algorithm for IBD patients based on the severity of both IBD and COVID-19 conditions. ${ }^{25}$ Irrespective of the severity of infection, corticosteroids need to be tapered to $20 \mathrm{mg}$ or below or switched to budesonide. Immunomodulators, tofacitinib and biologics need to be withhold for recommended duration. Regarding the duration of withholding, experience from the general population showed that symptoms developed within 14 days of close contact or positive test, and one recent study in nursing home patients reported that COVID-19 symptoms developed within 7 days in $89 \%$ of asymptomatic patients with positive viral tests. ${ }^{56,64}$ Based on these experiences, asymptomatic patients or closely exposed patients can resume immunomodulators, tofacitinib and biologics after 2 weeks of monitoring for symptoms associated with COVID-19. In symptomatic patients, such medications should be withhold until at least 10-14 days after symptoms developed. 
Table 1. IBD Medications during COVID-19 Pandemic

\begin{tabular}{|c|c|c|c|c|c|}
\hline \multirow{3}{*}{ Medication } & \multicolumn{4}{|c|}{ IBD in remission } & \multirow{3}{*}{ Active IBD } \\
\hline & \multicolumn{2}{|c|}{ No infection ${ }^{a}$} & \multirow{2}{*}{ Asymptomatic infection } & \multirow{2}{*}{ Symptomatic infection } & \\
\hline & New start & Dose escalation & & & \\
\hline 5-ASA & Yes & Yes & Continue & Continue & \multirow{8}{*}{$\begin{array}{l}\text { No medication } \\
\text { reduction } \\
\text { Careful consideration } \\
\text { about treatment } \\
\text { escalation }\end{array}$} \\
\hline Budesonide & Yes & Yes & Continue & Continue & \\
\hline Corticosteroid & No & No & $\begin{array}{l}\text { Recommend taper to lower } \\
\text { than } 20 \mathrm{mg}\end{array}$ & $\begin{array}{l}\text { Recommend taper to lower than } \\
20 \mathrm{mg}\end{array}$ & \\
\hline $\begin{array}{l}\text { Thiopurine/ } \\
\text { Methotrexate }\end{array}$ & No & No & $\begin{array}{l}\text { Withhold for } 2 \text { weeks of } \\
\text { symptoms free state }\end{array}$ & $\begin{array}{l}\text { Withhold at least } 14 \text { days and } 3 \text { days } \\
\text { of recovery or negative test }\end{array}$ & \\
\hline Anti-TNF & Yes $^{c}$ & Yes & $\begin{array}{l}\text { Withhold for } 2 \text { weeks of } \\
\text { symptoms free state }\end{array}$ & $\begin{array}{l}\text { Withhold at least } 14 \text { days and } 3 \text { days } \\
\text { of recovery }{ }^{b} \text { or negative test }\end{array}$ & \\
\hline Vedolizumab & Yes & Yes & $\begin{array}{l}\text { Withhold for } 2 \text { weeks of } \\
\text { symptoms free state }\end{array}$ & $\begin{array}{l}\text { Withhold at least } 14 \text { days and } 3 \text { days } \\
\text { of recovery or negative test }\end{array}$ & \\
\hline Ustekinumab & Yes & Yes & $\begin{array}{l}\text { Withhold for } 2 \text { weeks of } \\
\text { symptoms free state }\end{array}$ & $\begin{array}{l}\text { Withhold at least } 14 \text { days and } 3 \text { days } \\
\text { of recovery or negative test }\end{array}$ & \\
\hline Tofacitinib & No & No & $\begin{array}{l}\text { Withhold for } 2 \text { weeks of } \\
\text { symptoms free state }\end{array}$ & $\begin{array}{l}\text { Withhold at least } 14 \text { days and } 3 \text { days } \\
\text { of recovery or negative test }\end{array}$ & \\
\hline
\end{tabular}

${ }^{a}$ Most experts recommend continuing immunosuppressive treatment if the patients are already on stable maintenance. In patients on combination with anti-TNF and immunomodulators are recommended to stop immunomodulators if they are in remission.

${ }^{b}$ Defined as no fever and improved respiratory symptoms.

'When considering initiation of anti-TNF during pandemic, monotherapy is recommended.

IBD, inflammatory bowel disease; COVID-19, coronavirus disease 2019; 5-ASA, 5-aminosalicylates; TNF, tumor necrosis factor.

Re-start of medication in symptomatic COVID-19 patients could be considered after at least 3 days of no fever and improvement of respiratory symptoms or 2 consecutive negative test results. ${ }^{11,56,65}$

Because active IBD itself is one of the poor prognostic factors of COVID-19, the treatment should not be reduced in patients with moderately to severely active $\mathrm{IBD} .^{24}$ In addition, workup on the cause of flare-ups also should be considered. Although the IBD medications were not risk factors of adverse outcomes, the treatment escalation needs to be careful considering the risk and benefit of the drugs on COVID-19. ${ }^{24,25}$ The suggestions for the medical treatment of IBD in the COVID-19 era are summarized in Table 1.

In IBD patients hospitalized for COVID-19, treatment for the infection should be considered first. Anti-inflammatory, anti-cytokine, and viral therapies must be considered in patients with moderate-to-severe COVID-19. Novel therapies against COVID-19, including antiviral agents, anti-TNF- $\alpha$, antiIL-6 (tocilizumab), and JAK inhibitor (baricitinib) are undergoing clinical trials. ${ }^{66-68}$ However, it is challenging to treat patients with both acute severe UC and COVID-19 pneumonia. The BSG guidelines recommend $100 \mathrm{mg}$ hydrocortisone every 6 hours as the first-line therapy, and infliximab monother- apy could also be considered. ${ }^{35}$ Regarding high-dose steroids, one recent clinical trial with patients under mechanical ventilator showed that adding dexamethasone $6 \mathrm{mg}$ (equivalent dose of $32 \mathrm{mg}$ methylprednisolone or $160 \mathrm{mg}$ hydrocortisone) reduced the mortality rate. ${ }^{69}$ The decision regarding colectomy after failure of steroid or rescue therapy should not be hes-

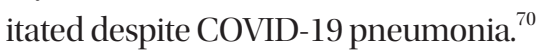

\section{CONCLUSION}

Based on current data, the risk of COVID-19 does not seem to increase in patients with IBD, and medications used for IBD do not increase this risk. Unless the patients have confirmed COVID-19 infection, all drugs except high-dose corticosteroids should be continued during the pandemic. Prevention of IBD relapse due to sudden interruption of medication is important for better patient outcomes. In addition, it is vital to adhere to general recommendations such as social distancing, wearing facial masks, and vaccination, especially for pneumococcal infections and influenza. Because we still have limited evidence, more data regarding optimal management and clinical outcomes are needed. 


\section{ADDITIONAL INFORMATION}

\section{Funding Source}

The authors received no financial support for the research, authorship, and/or publication of this article.

\section{Conflict of Interest}

No potential conflict of interest relevant to this article was reported.

\section{Author Contribution}

Conceptualization: Kim KO, Jang BI. Writing the original draft: Kim KO. Writing review and editing: Kim KO, Jang BI. Supervision: Jang BI. Approval of final manuscripts: all authors.

\section{ORCID}

Kim KO

Jang BI

https://orcid.org/0000-0001-5799-7436

https://orcid.org/0000-0002-3037-9272

\section{REFERENCES}

1. Wu F, Zhao S, Yu B, et al. A new coronavirus associated with human respiratory disease in China. Nature 2020;579:265-269.

2. Zhou P, Yang XL, Wang XG, et al. A pneumonia outbreak associated with a new coronavirus of probable bat origin. Nature 2020;579:270-273.

3. Wu Z, McGoogan JM. Characteristics of and important lessons from the coronavirus disease 2019 (COVID-19) outbreak in China: summary of a report of 72314 cases from the Chinese Center for Disease Control and Prevention. JAMA 2020; 323:1239-1242.

4. Chen R, Liang W, Jiang M, et al. Risk factors of fatal outcome in hospitalized subjects with coronavirus disease 2019 from a nationwide analysis in China. Chest 2020;158:97-105.

5. Du Y, Tu L, Zhu P, et al. Clinical features of 85 fatal cases of COVID-19 from Wuhan: a retrospective observational study. Am J Respir Crit Care Med 2020;201:1372-1379.

6. Mao R, Liang J, Shen J, et al. Implications of COVID-19 for patients with pre-existing digestive diseases. Lancet Gastroenterol Hepatol 2020;5:425-427.

7. Norsa L, Indriolo A, Sansotta N, Cosimo P, Greco S, D'Antiga L. Uneventful course in patients with inflammatory bowel disease during the severe acute respiratory syndrome coronavirus 2 outbreak in Northern Italy. Gastroenterology 2020;159: 371-372.

8. Neumann H, Emura F, Bokemeyer B, et al. Practical advice for management of inflammatory bowel diseases patients during the COVID-19 pandemic: World Endoscopy Organization Statement. Dig Endosc 2020;32:658-662.

9. Mao R, Qiu Y, He JS, et al. Manifestations and prognosis of gastrointestinal and liver involvement in patients with COVID-19: a systematic review and meta-analysis. Lancet Gastroenterol Hepatol 2020;5:667-678.

10. Pan L, Mu M, Yang P, et al. Clinical characteristics of COVID-19 patients with digestive symptoms in Hubei, China: a descriptive, cross-sectional, multicenter study. Am J Gastroenterol 2020;115:766-773.

11. Xiao F, Tang M, Zheng X, Liu Y, Li X, Shan H. Evidence for gastrointestinal infection of SARS-CoV-2. Gastroenterology 2020; 158:1831-1833.

12. Zhang H, Li HB, Lyu JR, et al. Specific ACE2 expression in small intestinal enterocytes may cause gastrointestinal symptoms and injury after 2019-nCoV infection. Int J Infect Dis 2020;96:19-24.

13. Jablaoui A, Kriaa A, Mkaouar H, et al. Fecal serine protease profiling in inflammatory bowel diseases. Front Cell Infect Microbiol 2020;10:21.

14. Allocca M, Fiorino G, Zallot C, et al. Incidence and patterns of COVID-19 among inflammatory bowel disease patients from the Nancy and Milan Cohorts. Clin Gastroenterol Hepatol 2020;18:2134-2135.

15. Taxonera C, Sagastagoitia I, Alba C, Mañas N, Olivares D, Rey E. 2019 novel coronavirus disease (COVID-19) in patients with inflammatory bowel diseases. Aliment Pharmacol Ther 2020;52:276-283.

16. Gubatan J, Levitte S, Balabanis T, Patel A, Sharma A, Habtezion A. SARS-CoV-2 testing, prevalence, and predictors of COVID-19 in patients with inflammatory bowel disease in Northern California. Gastroenterology 2020;159:1141-1144.

17. Wong E, Cohen T, Romi E, et al. Harnessing the natural inhibitory domain to control TNF $\alpha$ converting enzyme (TACE) activity in vivo. Sci Rep 2016;6:35598.

18. Ferreira-Duarte M, Estevinho MM, Duarte-Araújo M, Magro F, Morato M. Unraveling the role of ACE2, the binding receptor for SARS-CoV-2, in inflammatory bowel disease. Inflamm Bowel Dis 2020;26:1787-1795.

19. Burgueño JF, Reich A, Hazime H, et al. Expression of SARSCoV-2 entry molecules ACE2 and TMPRSS2 in the gut of patients with IBD. Inflamm Bowel Dis 2020;26:797-808.

20. Toruner M, Loftus EV Jr, Harmsen WS, et al. Risk factors for opportunistic infections in patients with inflammatory bowel disease. Gastroenterology 2008;134:929-936. 
21. Tosca J, Garcia N, Pascual I, et al. Clinical assessment of risk factors for infection in inflammatory bowel disease patients. Int J Colorectal Dis 2020;35:491-500.

22. Aberra FN, Lichtenstein GR. Methods to avoid infections in patients with inflammatory bowel disease. Inflamm Bowel Dis 2005;11:685-695.

23. Anikhindi SA, Kumar A, Arora A. COVID-19 in patients with inflammatory bowel disease. Expert Rev Gastroenterol Hepatol 2020;14:1187-1193.

24. Bezzio C, Saibeni S, Variola A, et al. Outcomes of COVID-19 in 79 patients with IBD in Italy: an IG-IBD study. Gut 2020;69: 1213-1217.

25. Rubin DT, Feuerstein JD, Wang AY, Cohen RD. AGA clinical practice update on management of inflammatory bowel disease during the COVID-19 pandemic: expert commentary. Gastroenterology 2020;159:350-357.

26. IOIBD. IOIBD update on COVID19 for patients with Crohn's disease and ulcerative colitis [Internet]. c2020 [cited 2020 Nov 24]. https://ioibd.org/ioibd-update-on-covid19-for-patientswith-crohns-disease-and-ulcerative-colitis/.

27. ECCO. 1st Interview COVID-19 ECCO Taskforce [Internet]. c2020 [cited 2020 Mar 27]. https://ecco-ibd.eu/images/6_ Publication/6_8_Surveys/1st_interview_COVID-19\%20ECCOTaskforce_published.pdf.

28. Ooi CJ, Hilmi I, Banerjee R, et al. Best practices on immunomodulators and biologic agents for ulcerative colitis and Crohn's disease in Asia. Intest Res 2019;17:285-310.

29. Ling KL, Hilmi I, Raja Ali RA, et al. Asian Pacific Association of Gastroenterology (APAGE) Inflammatory Bowel Disease (IBD) Working Party guidelines on IBD management during the COVID-19 pandemic. JGH Open 2020;4:320-323.

30. Brenner EJ, Ungaro RC, Gearry RB, et al. Corticosteroids, but not TNF antagonists, are associated with adverse COVID-19 outcomes in patients with inflammatory bowel diseases: results from an international registry. Gastroenterology 2020; 159:481-491.

31. Peter JV, John P, Graham PL, Moran JL, George IA, Bersten A. Corticosteroids in the prevention and treatment of acute respiratory distress syndrome (ARDS) in adults: meta-analysis. BMJ 2008;336:1006-1009.

32. Stockman LJ, Bellamy R, Garner P. SARS: systematic review of treatment effects. PLoS Med 2006;3:e343.

33. Arabi YM, Mandourah Y, Al-Hameed F, et al. Corticosteroid therapy for critically ill patients with Middle East respiratory syndrome. Am J Respir Crit Care Med 2018;197:757-767.

34. World Health Organization (WHO). Clinical management of
COVID-19 [Internet]. c2020 [cited 2020 Nov 24]. https://www. who.int/publications-detail-redirect/clinical-management-ofcovid-19.

35. Din S, Kent A, Pollok RC, et al. Adaptations to the British Society of Gastroenterology guidelines on the management of acute severe UC in the context of the COVID-19 pandemic: a RAND appropriateness panel. Gut 2020;69:1769-1777.

36. Cheng KW, Cheng SC, Chen WY, et al. Thiopurine analogs and mycophenolic acid synergistically inhibit the papain-like protease of Middle East respiratory syndrome coronavirus. Antiviral Res 2015;115:9-16.

37. Zhou Y, Hou Y, Shen J, Huang Y, Martin W, Cheng F. Networkbased drug repurposing for novel coronavirus 2019-nCoV/ SARS-CoV-2. Cell Discov 2020;6:14.

38. Wisniewski A, Kirchgesner J, Seksik P, et al. Increased incidence of systemic serious viral infections in patients with inflammatory bowel disease associates with active disease and use of thiopurines. United European Gastroenterol J 2020;8: 303-313.

39. Zingone F, Buda A, Savarino EV. Screening for active COVID-19 infection and immunization status prior to biologic therapy in IBD patients at the time of the pandemic outbreak. Dig Liver Dis 2020;52:604-605.

40. Festa S, Aratari A, De Biasio F, Fascì-Spurio F, Papi C. Screening for active COVID-19 infection prior to biologic therapy in IBD patients: let's not increase our uncertainty without reducing our concerns. Dig Liver Dis 2020;52:1246-1247.

41. Gordon JP, McEwan PC, Maguire A, Sugrue DM, Puelles J. Characterizing unmet medical need and the potential role of new biologic treatment options in patients with ulcerative colitis and Crohn's disease: a systematic review and clinician surveys. Eur J Gastroenterol Hepatol 2015;27:804-812.

42. Al-Ani AH, Prentice RE, Rentsch CA, et al. Review article: prevention, diagnosis and management of COVID-19 in the IBD patient. Aliment Pharmacol Ther 2020;52:54-72.

43. Turner D, Huang Y, Martín-de-Carpi J, et al. Corona virus disease 2019 and paediatric inflammatory bowel diseases: global experience and provisional guidance (March 2020) from the Paediatric IBD Porto Group of European Society of Paediatric Gastroenterology, Hepatology, and Nutrition. J Pediatr Gastroenterol Nutr 2020;70:727-733.

44. Bye WA, Jairath V, Travis SP. Systematic review: the safety of vedolizumab for the treatment of inflammatory bowel disease. Aliment Pharmacol Ther 2017;46:3-15.

45. Hanauer SB, Sandborn WJ, Feagan BG, et al. IM-UNITI: threeyear efficacy, safety, and immunogenicity of ustekinumab 
treatment of Crohn's disease. J Crohns Colitis 2020;14:23-32.

46. Moćko P, Kawalec P, Pilc A. Safety profile of biologic drugs in the therapy of Crohn disease: a systematic review and network meta-analysis. Pharmacol Rep 2016;68:1237-1243.

47. Moćko P, Kawalec P, Pilc A. Safety profile of biologic drugs in the therapy of ulcerative colitis: a systematic review and network meta-analysis. Pharmacotherapy 2016;36:870-879.

48. Wollenhaupt J, Lee EB, Curtis JR, et al. Safety and efficacy of tofacitinib for up to 9.5 years in the treatment of rheumatoid arthritis: final results of a global, open-label, long-term extension study. Arthritis Res Ther 2019;21:89.

49. Haberman R, Axelrad J, Chen A, et al. Covid-19 in immunemediated inflammatory diseases: case series from New York. N Engl J Med 2020;383:85-88.

50. Winthrop KL, Melmed GY, Vermeire S, et al. Herpes zoster infection in patients with ulcerative colitis receiving tofacitinib. Inflamm Bowel Dis 2018;24:2258-2265.

51. Klok FA, Kruip MJ, van der Meer NJ, et al. Incidence of thrombotic complications in critically ill ICU patients with COVID-19. Thromb Res 2020;191:145-147.

52. Harigai M. Growing evidence of the safety of JAK inhibitors in patients with rheumatoid arthritis. Rheumatology (Oxford) 2019;58(Suppl 1):i34-i42.

53. Weisshof R, Aharoni Golan M, Sossenheimer PH, et al. Realworld experience with tofacitinib in IBD at a tertiary center. Dig Dis Sci 2019;64:1945-1951.

54. Kennedy NA, Jones GR, Lamb CA, et al. British Society of Gastroenterology guidance for management of inflammatory bowel disease during the COVID-19 pandemic. Gut 2020;69: 984-990.

55. Magro F, Rahier JF, Abreu C, et al. Inflammatory bowel disease management during the COVID-19 outbreak: the ten do's and don'ts from the ECCO-COVID taskforce. J Crohns Colitis 2020; 14(Supplement_3):S798-S806.

56. Aysha AA, Rentsch C, Prentice R, et al. Practical management of inflammatory bowel disease patients during the COVID-19 pandemic: expert commentary from the Gastroenterological Society of Australia Inflammatory Bowel Disease faculty. Intern Med J 2020;50:798-804.

57. Santarpia JL, Rivera DN, Herrera VL, et al. Aerosol and surface contamination of SARS-CoV-2 observed in quarantine and isolation care. Sci Rep 2020;10:12732.

58. Wu Y, Guo C, Tang L, et al. Prolonged presence of SARS-CoV-2 viral RNA in faecal samples. Lancet Gastroenterol Hepatol
2020;5:434-435.

59. Iacucci M, Cannatelli R, Labarile N, et al. Endoscopy in inflammatory bowel diseases during the COVID-19 pandemic and post-pandemic period. Lancet Gastroenterol Hepatol 2020;5:598-606.

60. Laine L, Kaltenbach T, Barkun A, et al. SCENIC international consensus statement on surveillance and management of dysplasia in inflammatory bowel disease. Gastrointest Endosc 2015;81:489-501.

61. Lamb CA, Kennedy NA, Raine T, et al. British Society of Gastroenterology consensus guidelines on the management of inflammatory bowel disease in adults. Gut 2019;68(Suppl 3):s1-s106.

62. Han J, Kim EY. Sharing our experience of operating an endoscopy unit in the midst of a COVID-19 outbreak. Clin Endosc 2020;53:243-245.

63. Surveillance Epidemiology of Coronavirus (COVID-19) Under Research Exclusion (SECURE-IBD). Current data [Internet]. c2020 [cited 2020 Nov 24]. https://covidibd.org/currentdata/.

64. Arons MM, Hatfield KM, Reddy SC, et al. Presymptomatic SARS-CoV-2 infections and transmission in a skilled nursing facility. N Engl J Med 2020;382:2081-2090.

65. Siegel CA, Christensen B, Kornbluth A, et al. Guidance for restarting inflammatory bowel disease therapy in patients who withheld immunosuppressant medications during COVID-19. J Crohns Colitis 2020;14(Supplement_3):S769-S773.

66. Zhang W, Zhao Y, Zhang F, et al. The use of anti-inflammatory drugs in the treatment of people with severe coronavirus disease 2019 (COVID-19): the perspectives of clinical immunologists from China. Clin Immunol 2020;214:108393.

67. Monteleone G, Sarzi-Puttini PC, Ardizzone S. Preventing COVID-19-induced pneumonia with anticytokine therapy. Lancet Rheumatol 2020;2:e255-e256.

68. Feldmann M, Maini RN, Woody JN, et al. Trials of anti-tumour necrosis factor therapy for COVID-19 are urgently needed. Lancet 2020;395:1407-1409.

69. RECOVERY Collaborative Group, Horby P, Lim WS, et al. Dexamethasone in hospitalized patients with Covid-19. N Engl J Med 2021;384:693-704.

70. Gajendran M, Perisetti A, Aziz M, et al. Inflammatory bowel disease amid the COVID-19 pandemic: impact, management strategies, and lessons learned. Ann Gastroenterol 2020;33: 591-602. 